\title{
Voltage Clamp Analysis of Tetrodotoxin-sensitive and -insensitive Sodium Channels in Rat Muscle Cells Developing In Vitro'
}

\author{
TOHRU GONOI, SCOTT J. SHERMAN, AND WILLIAM A. CATTERALL ${ }^{2}$
}

Department of Pharmacology, University of Washington, Seattle, Washington 98195

\begin{abstract}
Sodium currents in cultured rat muscle cells converted to myoballs by treatment with colchicine were recorded using a giga-ohm seal voltage clamp procedure in the whole cell configuration. The mean peak $\mathrm{Na}^{+}$conductance of the myoballs was $90 \mathrm{pS} / \mu \mathrm{m}^{2}$ of surface membrane. Half-maximal activation of $\mathrm{Na}^{+}$currents was observed for test pulses to $-31 \mathrm{mV}$ and half-maximal inactivation was observed for prepulses to $-74 \mathrm{mV}$. Titration of the inhibition of $\mathrm{Na}^{+}$currents by tetrodotoxin (TTX) yielded a biphasic inhibition curve consistent with the presence of two classes of $\mathrm{Na}^{+}$channels differing in affinity for TTX. The TTX-sensitive channels carried $28 \%$ of the $\mathrm{Na}^{+}$current and had an apparent $K_{D}$ for TTX of $13 \mathrm{nM}$ at $20^{\circ} \mathrm{C}$. The TTX-insensitive $\mathrm{Na}^{+}$channels had an apparent $K_{D}$ for TTX of $3.2 \mu \mathrm{M}$. Inhibition of TTX-insensitive $\mathrm{Na}^{+}$channels by TTX was enhanced by repetitive stimulation of the myoballs at $2 \mathrm{~Hz}$, whereas the inhibition of $T T X$ sensitive $\mathrm{Na}^{+}$channels by TTX was not frequency dependent. We conclude that rat muscle cells developing in vitro synthesize physiologically functional, $\mathrm{TTX}$-sensitive $\mathrm{Na}^{+}$channels in the absence of innervation. These channels, which are characteristic of adult skeletal muscle, function in parallel with TTX-insensitive $\mathrm{Na}^{+}$channels that are present in embryonic muscle.
\end{abstract}

Voltage-sensitive sodium channels mediate the rapid sodium influx during the depolarizing phase of the action potential in vertebrate skeletal muscle. In adult skeletal muscle, these sodium channels are specifically inhibited by tetrodotoxin (TTX) and saxitoxin (STX) binding at neurotoxin receptor site 1 with a $K_{D}$ of 1 to $10 \mathrm{nM}$ (reviewed by Ritchie and Royart, 1977; Catterall, 1980). In felal manmmalian muscle in vivo (Harris and Marshall, 1973) or in cell culture (Kidokoro et al., 1975; Catterall, 1976; Sastre and Podleski, 1976; Stallcup and Cohn, 1976) and in denervated adult muscle (Harris and Thesleff, 1971; Pappone, 1980), there are sodium channels which are relatively insensitive to inhibition by these toxins having an apparent $K_{D}$

Received December 28, 1984; Revised February 22, 1985;

Accepted February 24, 1985

${ }^{1}$ This work was supported by a research grant from the Muscular Dystrophy Association and Grant BNS 80-21619 from the National Science Foundation to W. A. C., and by a Department of Defense University Research Instrumentation grant to Bertil Hille and W. A. C. We would like to thank Professor Bertil Hille, Department of Physiology and Biophysics, University of Washington, for valuable advice on methods for voltage clamp recording from myoballs.

${ }^{2}$ To whom correspondence should be addressed. of approximately $\uparrow \mu \mathrm{M}$. TTX-insensitive sodium channels do not appear in denervated muscle of the nonmammalian vertebrates that have been examined (Nasledov and Thesleff, 1974; Cullen et al., 1975).

TTX-sensitive and -insensitive sodium channels in mammalian skeletal muscle celis have similar affinity for the alkaloids veratridine, aconitine, and batrachotoxin, which cause persistent activation by interaction with neurotoxin receptor site 2 on the sodium channel (Albuquerque and Warnick, 1972; Catterall, 1976; Lawrence and Catterall, 1981a). In contrast, TTX-insensitive sodium channels bind sea anemone toxins with higher affinity and scorpion toxins bind with lower affinity than do TTX-sensitive sodium channels at neurotoxin receptor site 3 (Lawrence and Catterall, 1981a, b; Sherman et al., 1983; Frelin et al., 1984a, b). These results suggest that TTXsensitive and -insensitive sodium channels represent distinct pharmacological subtypes with differing affinity and specificity at two neurotoxin receptor sites.

Myocytes maintained in cell culture fuse to form multinucleated myotubes which are electrically excitable and contract spontaneously (reviewed by Nelson, 1975). TTX-insensitive sodium channels are present in mononucleated myoblasts as well as in mature cultures of myotubes (Catterall, 1976; Frelin et al., 1983). Early electrophysiological and ion flux studies of cultured rat muscle cells did not detect TTX-sensitive sodium channels (Kidokoro et al., 1975; Catterall, 1976; Sastre and Podleski, 1976; Stallcup and Cohn, 1976; Lawrence and Catterall, 1981a). However, two recent reports show that these cells have a substantial complement of high affinity binding sites for STX which have the characteristics of TTX-sensitive sodium channels (Frelin et al., 1983; Sherman et al., 1983). Sherman et al. (1983) concluded that these represent physiologically functional TTX-sensitive sodium channels because spontaneous contraction was inhibited by low concentrations of TTX, and ${ }^{22} \mathrm{Na}^{+}$influx mediated by sodium channels activated with veratridine plus scorpion toxin was inhibited by TTX in a biphasic manner consistent with the presence of both TTX-sensitive and -insensitive sodium channels. In contrast, Frelin et al. (1983) concluded that the high affinity STXbinding sites were a physiologically inactive form of the $\Pi \mathrm{TX}$-sensitive sodium channels because the action potential was unaffected by $50 \mathrm{nM}$ TTX and because ${ }^{22} \mathrm{Na}$ influx mediated by sodium channels activated with veratridine and sea anemone toxin was inhibited by TTX in a monophasic manner, suggesting the presence of only TTXinsensitive sodium channels.

None of the methods used in these two previous studies provides an unambiguous test of the presence of physiologically active, TTXsensitive sodium channels (see "Discussion"). Recording of sodium currents activated by depolarization under voltage clamp control is the most rigorous method to study sodium channel function. The membrane potential of skeletal muscle myotubes in cell culture cannot be effectively controlled by a microelectrode voltage clamp because of cylindrical geometry of the cells. Fukuda et al. (1976) 
showed that conversion of the elongated myotubes to spherical "myoballs" by treatment with colchicine allowed accurate recording of slow whole cell membrane currents with a two-microelectrode voltage clamp apparatus. However, the sodium current was activated too rapidly for good resolution with this method (Fukuda et al., 1976). Therefore, we have used the giga-ohm seal patch voltage clamp method of Hamill et al. (1981) in the whole cell configuration to make a more definitive assessment of the presence of functional TTX-sensitive sodium channels in rat muscle cells converted to myoballs with colchicine.

\section{Materials and Methods}

Materials. Materials were obtained from the following sources: TTX and calf skin collagen, Calbiochem; tetraethylammonium (TEA) chloride and colchicine, Sigma Chemical Co.; horse serum and newborn calf serum, KC Biological Inc.; and Dulbecco-Vogt modified Eagle's essential medium (DMEM), Grand Island Biological Co.

Primary cell culture. Skeletal muscle cells were obtained from the forelimbs of 20-day-old embryonic rats and prepared as described previously (Lawrence and Catterall, 1981b). Cells were seeded at a density of $1 \times 10^{5}$ cells/ 35 -mm plastic dish (Falcon) coated with collagen. The culture medium consisted of $10 \%$ horse serum, $5 \%$ newborn calf serum, and $85 \%$ DMEM. After day 4 , the culture medium was supplemented with $1 \times 10^{-7}$ or $1 \times$ $10^{-6} \mathrm{M}$ colchicine, resulting in formation of myoballs within $24 \mathrm{hr}$.

Voltage clamp recordings. Myoballs formed from rat muscle cells maintained in culture for 5 to 10 days were used for voltage clamp experiments. The culture medium was replaced with one of the following recording media: (1) normal mammalian Ringcr's solution (150 mM NaCl, $5 \mathrm{~mm} \mathrm{KCl,} 1.5 \mathrm{~mm}$ $\mathrm{CaCl}_{2}, 1 \mathrm{mM} \mathrm{MgCl}_{2}, 5 \mathrm{~mm}$ glucose, $5 \mathrm{mM} \mathrm{Na}^{+}$HEPES, pH 7.4), (2) $\mathrm{K}^{+}$-free Ringer's solution ( $150 \mathrm{~mm} \mathrm{NaCl}, 1.5 \mathrm{~mm} \mathrm{CaCl}, 1 \mathrm{~mm} \mathrm{MgCl}, 5 \mathrm{~mm}$ glucose, 5 rIM Na HEPES, $\mathrm{pH}$ 7.4), or (3) $\mathrm{K}^{+}$-free TEA-Ringer's solulion (120 mM TEA, $35 \mathrm{~mm} \mathrm{NaCl}, 1.5 \mathrm{mM} \mathrm{CaCl}_{2}, 1 \mathrm{~mm} \mathrm{MgCl}, 5 \mathrm{~mm}$ glucose, $5 \mathrm{~mm} \mathrm{Na}$ HEPES, $\mathrm{pH}$ 7.4). Recordings were made on myoballs with diameters of 23 to $38 \mu \mathrm{m}$ at room temperature $\left(20 \pm 1^{\circ} \mathrm{C}\right)$.

The voltage clamp was based on the one-pipette giga-ohm seal whole cell recording technique (Hamill et al., 1981). A circuit for voltage clamp allowed series resistance compensation of up to 1 megohm. Details of the recordings were described previously (Gonoi et al., 1984). Tip resistances of the pipettes were 0.1 to 0.3 megohms in mammalian Ringer's solution. The internal pipette solution was as follows: $145 \mathrm{~mm} \mathrm{CsF}, 10 \mathrm{~mm} \mathrm{NaF}, 5 \mathrm{~mm}$ EGTA, pH 7.2. $\mathrm{K}^{+}$current was efficiently blocked by $\mathrm{Cs}^{+}$ions in the micropipette. Currents were displayed on a storage oscilloscope and photographed. Surface area of myoballs was calculated from the diameter of the myoballs under a microscope, since they are spherical. Total capacitance of the membrane was calculated from the area under the capacity current transient in a voltage step from -90 to $-97.5 \mathrm{mV}$. Na ${ }^{+}$conductance, $G_{\mathrm{Na}}$ was calculated from peak currents by the relation

$$
G_{\mathrm{Na}}=I_{\mathrm{Na}} /\left(E-E_{\mathrm{Na}}\right)
$$

where $I_{\mathrm{Na}}$ is $\mathrm{Na}^{+}$current, $E$ is membrane potential, and $E_{\mathrm{Na}}$ is the reversa potential of the $\mathrm{Na}^{+}$current measured for each $\mathrm{G}_{\mathrm{Na}}$ determination.

For measurements of voltage-dependent activation and inactivation of $\mathrm{Na}^{+}$channels, the holding potential of the cell was maintained at $-90 \mathrm{mV}$. For measurement of activation, the membrane was hyperpolarized in a prepulse to $-135 \mathrm{mV}$ for $90 \mathrm{msec}$ to remove inactivation of $\mathrm{Na}^{+}$channels, and then depolarized to test pulse potentials from -75 to $+75 \mathrm{mV}$ for 10 msec. For measurement of the voltage dependence of inactivation, the potential of the 90-msec prepulse was varied from $-135 \mathrm{mV}$ to $-30 \mathrm{mV}$ in intervals of $15 \mathrm{mV}$ and the cell was then stimulated with a test pulse to -15 $\mathrm{mV}$ for $10 \mathrm{msec}$. The voltage dependence of sodium channel activation shifted 10 to $20 \mathrm{mV}$ to more negative values over $60 \mathrm{~min}$ after making a seal. The values reported are those made as soon as the maximum seal resistance and current were attained.

For studying frequency dependence of the $T \mathrm{XX}$ action on sodium currents myoballs were stimulated with depolarizing test pulses to $-15 \mathrm{mV}$ at a frequency between 0.5 and $8 \mathrm{~Hz}$ from a holding potential of $-120 \mathrm{mV}$ without a prepulse.

Determination of the concentration dependence of $\pi \mathrm{X}$ action. The $\mathrm{Na}^{+}$ conductance of most myoballs was increased from 0 to $50 \%$ of the initial values in 5 lo 10 min after making a seal. TTX dose-response measurements were started after steady amplitude of sodium currents was obtained. TX dissolved in TEA-Ringer's was added to the dish either by perfusing the dish with a peristaltic pump or adding solution cumulatively to the top of the dish
In the latter case, multiple aliquots of TTX solution 3-fold more concentrated than the desired concentration were added to the dish from a pipette at several points more than $1 \mathrm{~cm}$ from the myoball. In either procedure, 6 to 10 min were allowed for $\Pi \mathrm{X}$ inhibition to reach steady state. These two procedures gave identical results. In some experiments, the TTX solution was washed out by perfusing with a peristaltic pump to examine recovery from the $\Pi X$ inhibition of $\mathrm{Na}^{+}$currents.

The inhibition of $\mathrm{Na}^{+}$currents by different concentrations of TTX was analyzed according to a two-site model in which a fraction, $F_{\mathrm{H}}$, of the $\mathrm{Na}^{+}$ current is mediated by $\mathrm{Na}^{+}$channels with a high affinity for $\Pi \mathrm{TX}$ characterized by the dissociation constant, $K_{H}$, and the remaining $\mathrm{Na}^{+}$current $\left(1-F_{H}\right)$ is mediated by $\mathrm{Na}^{+}$channels with low affinity for TTX characterized by the dissociation constant $K_{L}$ according to the equation

$$
\frac{G_{\mathrm{Na}}}{G_{\mathrm{Na}}{ }^{\max }}=1-\frac{F_{H}}{1+\frac{K_{H}}{[\pi \mathrm{X}]}}+\frac{1-F_{H}}{1+\frac{K_{L}}{[\pi \mathrm{TX}]}}
$$

Best fit values for $F_{H}, K_{H}$, and $K_{L}$ were determined by an iterative least squares curve-fitting procedure.

\section{Results}

$\mathrm{Na}^{+}$currents of rat myoballs. Because of their large surface area, rat myoballs have large whole cell sodium currents ranging up to $200 \mathrm{nA}$. In order to avoid series resistance artifacts in our current recordings, most experiments were carried out in a TEA-substituted mammalian Ringer's solution which contained $35 \mathrm{~mm} \mathrm{Na}^{+}$. Figure $1 A$ shows a family of $\mathrm{Na}^{+}$currents recorded from a 9-day-old rat myoball in culture. The myoball was placed in TEA-Ringer's and the cell membrane was stimulated by test pulses ranging from $-75 \mathrm{mV}$ to $+75 \mathrm{mV}$ following a $90-\mathrm{msec}$ prepulse to $-135 \mathrm{mV}$. Na ${ }^{+}$channels are activated within $3 \mathrm{msec}$ and were completely inactivated before the end of the $10-\mathrm{msec}$ test pulse period when the test potentials were more positive than $-15 \mathrm{mV}$. $\mathrm{Na}^{+}$currents of myoballs in normal Ringer's have similar kinetics (data not shown). Figure 2 illustrates the voltage dependence of steady-state activation and inactivation of the $\mathrm{Na}^{+}$currents of rat myoballs. The mean values of the membrane potentials for half-maximal activation and inactivation of the sodium channels in rat myoballs were $-30.9 \pm 8.9 \mathrm{mV}$ (SD; $n$ $=37)$ and $-74.3 \pm 7.8 \mathrm{mV}(n=10)$, respectively. The average

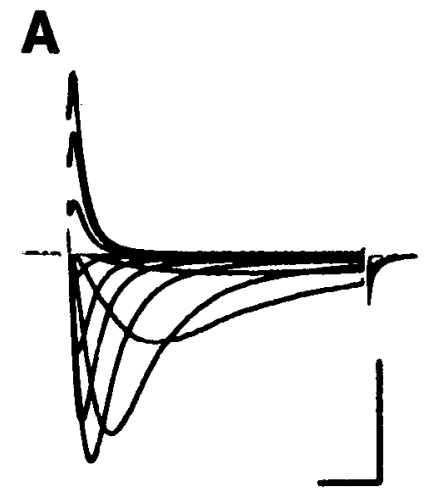

B

Figure $1 . \mathrm{Na}^{+}$currents from rat myoballs in culture. Rat myoblast cultures were prepared and myoballs were made as described under "Materials and Methods." A. The recording was made in TEA-substituted, low Na ${ }^{+}$Ringer's (see "Materials and Methods") 8 min after making a seal between a myoball and the micropipette. The recording micropipette contained $145 \mathrm{~mm}$ CsF ions which blocked outward $\mathrm{K}^{+}$current. The myoball was maintained at a holding potential of $-90 \mathrm{mV}$, hyperpolarized to $-135 \mathrm{mV}$ for $90 \mathrm{msec}$, and depolarized once per second to potentials from $-75 \mathrm{mV}$ to $+30 \mathrm{mV}$ in 15 $\mathrm{mV}$ intervals to elicit $\mathrm{Na}^{+}$currents. $B, \mathrm{Na}^{+}$currents from another rat myoball 90 min after making a seal between the membrane and the micropipette. The recording was made in normal Ringer's solution. The stimulus conditions were the same as in $A$ except that the first test pulse potential was $-90 \mathrm{mV}$. The inactivation of the $\mathrm{Na}^{+}$current was removed progressively and spontaneously after making a seal. Calibration, $2 \mathrm{msec}, 10 \mathrm{nA}$ for $A$ and $2 \mathrm{msec}$, $20 \mathrm{nA}$ for $B$. 


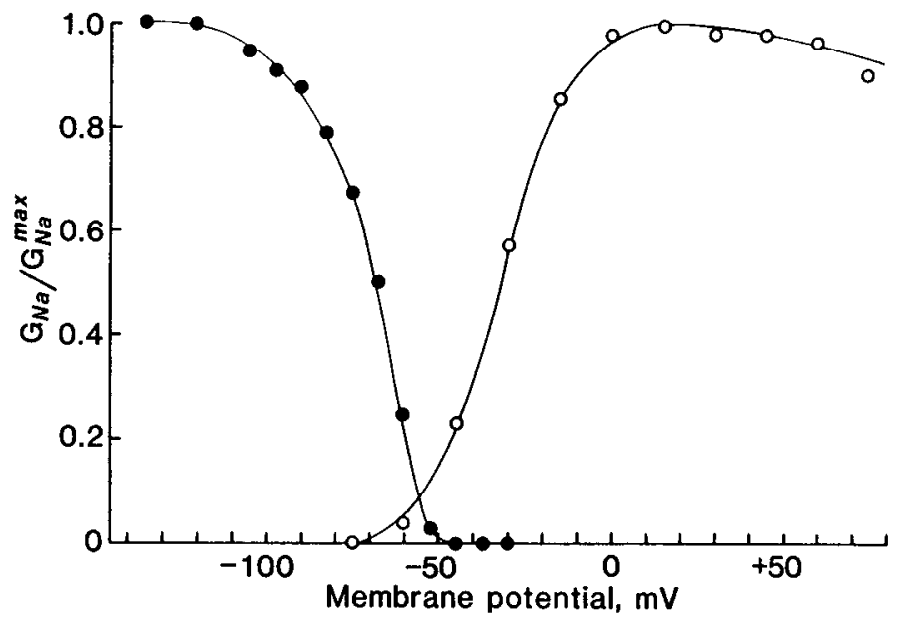

Figure 2. Voltage dependence of $\mathrm{Na}^{+}$channel activation and inactivation in rat myoballs. Voltage dependence of $\mathrm{Na}^{+}$channel activation $(\mathrm{O})$ and inactivation (-) was measured as described under "Materials and Methods." Normalized values for activation were calculated as the ratio of $\mathrm{Na}^{+}$conductance, $G_{\text {Na }}$, during a test pulse at the indicated membrane potential to that during a test pulse to $+15 \mathrm{mV}$. Normalized values for inactivation were calculated as a ratio of $I_{\mathrm{Na}}$ at each prepulse potential to that following a prepulse to $-135 \mathrm{mV}$.

maximum $\mathrm{Na}^{+}$conductance of myoballs maintained 5 to 10 days in vitro was $358 \pm 247 \mathrm{nS} /$ myoball $(n=37)$ or $90.3 \pm 60.0 \mathrm{pS} / \mu \mathrm{m}^{2}$ in TEA Ringcr's containing $35 \mathrm{~mm} \mathrm{Na}^{+}$. The ratio of the membrane capacitance to the observed surface area of myoballs was $1.09 \pm$ $0.41 \mu \mathrm{F} / \mathrm{cm}^{2}(n=21)$.

In nearly all recordings from myoballs made in normal or TEAsubstituted Ringer's solution, progressive removal of the $\mathrm{Na}^{+}$current inactivation was observed in 20 to 60 min after making a seal with a pipette (Fig. 1B). Although a systematic study was not made, removal of $\mathrm{K}^{+}$from the Ringer's solution seemed to prolong the time before this spontaneous removal of inactivation occurred. Therefore, all of the following experiments were carried out in $\mathrm{K}^{+}$-free Ringer's solution (medium 3 under "Materials and Methods"). In this $\mathrm{K}^{+}$depleted medium, we could consistently record for more than 60 min without loss of inactivation.

Measurement of $T T X$ sensitivity. Figure $3 A$ illustrates the average inhibition of $\mathrm{Na}^{+}$currents in 13 different myoballs by increasing concentrations of TTX. TTX inhibition of the $\mathrm{Na}^{+}$conductance began at $3 \mathrm{nM}$ and no conductance remained after the addition of $100 \mu \mathrm{M}$ TTX. The $\mathrm{Na}^{+}$conductance of the myoball decreased in a biphasic manner as the final concentration of TTX increased, suggesting that there are high and low affinity sites of $\Pi X$ action. In another series of experiments, TTX concentration was changed by perfusing the dish with increasing concentrations of TTX. Then, after a high concentration of TTX ( $3 \mu \mathrm{M}$ or $10 \mu \mathrm{M})$ was attained, the dish was washed with TEA-Ringer's without the toxin. The peak $\mathrm{Na}^{+}$conductance of these myoballs recovered to 68 to $87 \%$ of the original value obtained before perfusion with the toxin $(n=4)$. Thus, TTX reversibly inhibits $\mathrm{Na}^{+}$currents in rat myoballs across a broad concentration range.

In order to determine whelther the inhibition of $\mathrm{Na}^{+}$currents was consistent with the presence of two classes of functional $\mathrm{Na}^{+}$ channels differing in apparent $K_{D}$ for TTX, the average results from the 13 myoballs illustrated in Figure $3 A$ were plotted as an EadieHofstee plot as illustrated in Figure $3 B$. The $\mathrm{Na}^{+}$conductance blocked by $T T X$ is plotted after normalization to maximum $\mathrm{Na}^{+}$ conductance. Two different TTX receptor sites are suggested by the results. Analysis of the data using a two-site model for $\Pi X$ action (see "Materials and Methods") and an iterative least squares curve-fitting method gives average apparent dissociation constants $\left(K_{0}\right)$ for the high and low affinity binding sites of $13.1 \mathrm{~nm}$ and 3.2 $\mu \mathrm{M}$, respectively. For these cells, an average of $27.6 \%$ of the $\mathrm{Na}^{+}$ current was inhibited by TTX with an apparent $K_{D}$ of $13 \mathrm{nM}$ and $72.4 \%$ was inhibited with an apparent $K_{D}$ of $3.2 \mu \mathrm{M}$. The $K_{D}$ values for TTX inhibition of TTX-sensitive and -insensitive $\mathrm{Na}^{+}$channels are in close agreement with estimates of $21 \mathrm{nM}$ and $1.8 \mu \mathrm{M}$, respectively, from previous ion flux data (Sherman et al., 1983).

The results for each individual myoball were also analyzed by Eadie-Hofstee plots and curve fitting to derive estimates of these parameters. The mean $K_{0}$ values were $10.0 \pm 2 \mathrm{nM}(\mathrm{SEM})$ and 2.8 $\pm 0.3 \mu \mathrm{M}$ when analyzed by this method. The fraction of $\mathrm{Na}^{+}$ conductance with high affinity for TTX ranged from $7 \%$ to $59 \%$ with an average of $27.0 \pm 14.0 \%(\mathrm{SD})$ tor the 13 cells subjected to analysis.
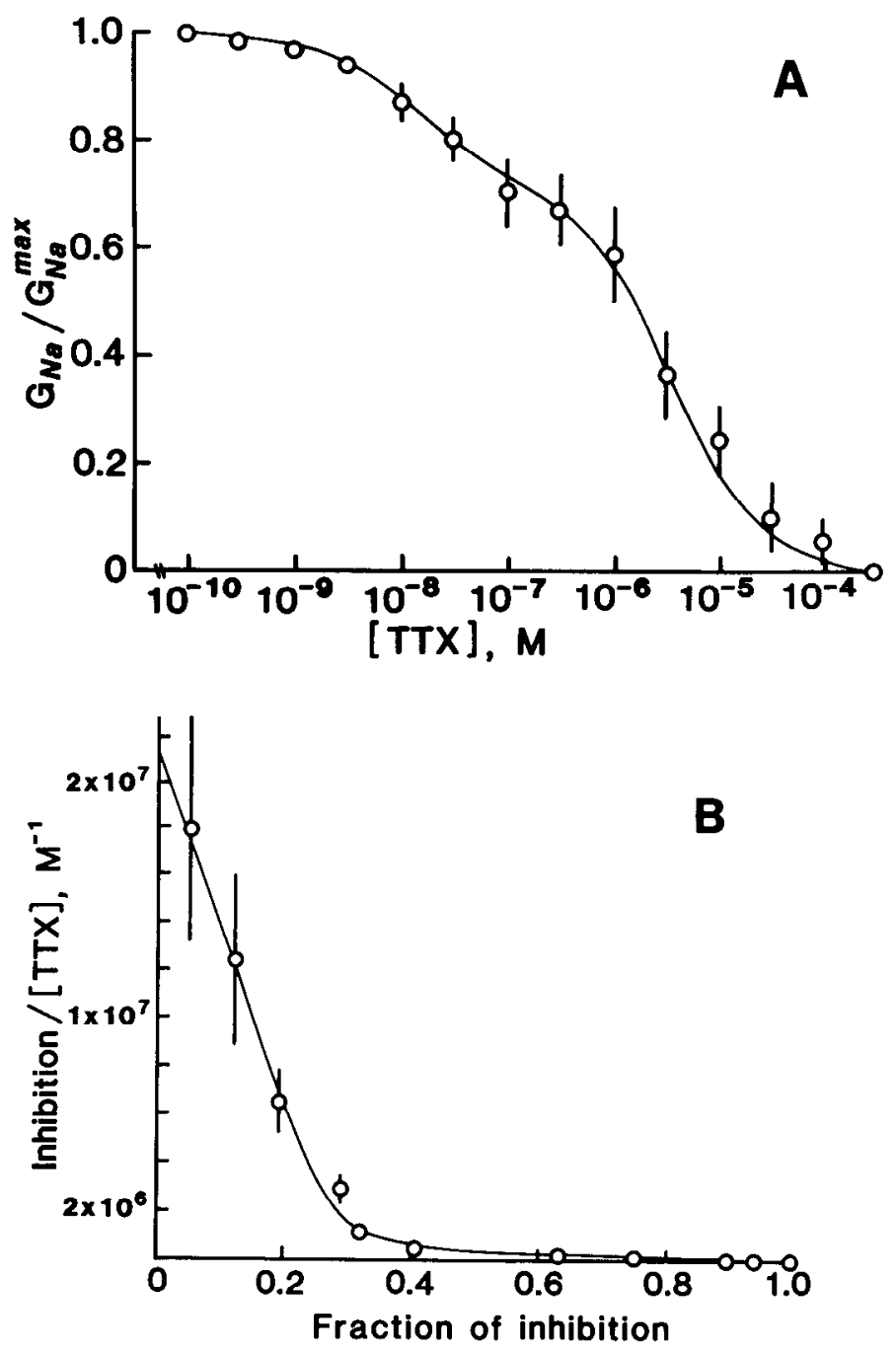

Figure 3. Concentration dependence of TTX inhibition of $\mathrm{Na}^{+}$currents. $A$, Giga-ohm seals were made on individual rat myoballs and $\mathrm{Na}^{+}$currents were recorded in TEA-Ringer's as described under "Materials and Methods." Following recording of control currents, the indicated concentrations of I IX were achieved by cumulative additions of TTX solution (11 myoballs) or by perfusion with TTX-containing TEA-Ringer's (2 myoballs), and peak $\mathrm{Na}^{+}$ conductance was determined as described under "Materials and Methods." Data from the two different methods of addition of TTX were similar and were pooled for analysis. Values of the mean of the normalized $\mathrm{Na}^{+}$conductance $\left(O, G_{\mathrm{Na}} / G_{\mathrm{Na}}{ }^{\text {max }}\right)$ and the SEM are plotted against $\Pi \mathrm{TX}$ concentration. The smooth curve represents a fit to the data with $F_{H}=0.276, K_{H}=13.1$ $\mathrm{nM}$, and $K_{L}=3.2 \mu \mathrm{M}$ as described under "Materials and Methods." $B$, The results of $A$ are presented as an Eadie-Hofstee plot. The smooth curve represents a fit to the data derived with the parameters described above. Vertical bars represent SEM. 


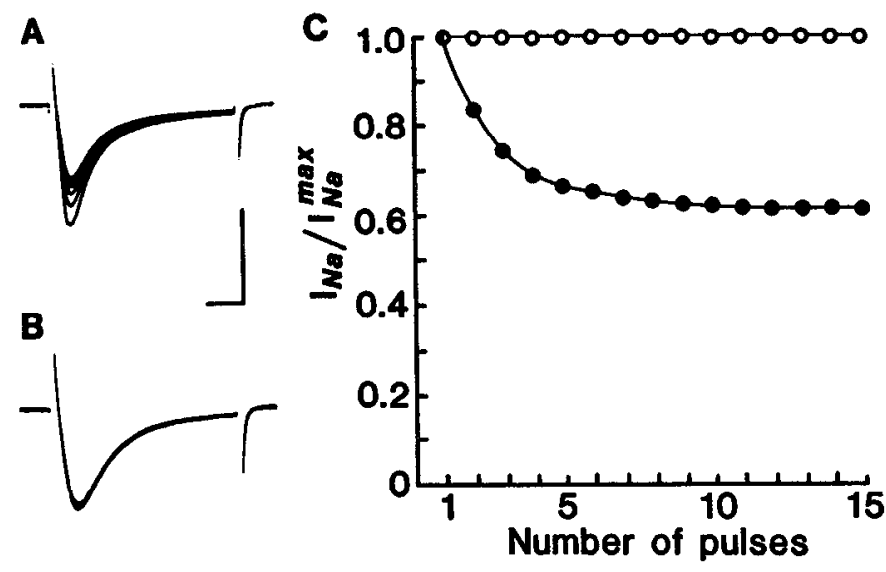

Figure 4. Frequency-dependent inhibition of $\mathrm{Na}^{+}$channels on rat myoballs by TTX. A, After control recordings in TEA-Ringer's, the recording medium was changed to $155 \mathrm{mM} \mathrm{Na}^{+}$Ringer's containing $1 \mu \mathrm{M} \mathrm{TTX}$. The high $\mathrm{Na}^{+}$ medium was used, since the currents were small because of steady-state inhibition of TTX. The myoball was maintained at a holding potential of -120 $\mathrm{mV}$. After a resting period of $3 \mathrm{~min}$, the cell was stimulated with depolarizing test pulses to $-15 \mathrm{mV}$ for $10 \mathrm{msec}$ at a frequency of $2 \mathrm{~Hz}$ to elicit $\mathrm{Na}^{+}$ currents. Traces of 10 currents were superimposed. Accumulative decrease of $\mathrm{Na}^{+}$current amplitude was observed during every depolarizing test pulse. In control recordings without $\Pi \mathrm{TX}$, there was no reduction of $\mathrm{Na}^{+}$currents during the repetitive stimulation under this stimulus conditions. $B, A$ similar experiment was carried out in the presence of $30 \mathrm{nM}$ TTX in TEA-Ringer's. $C$, The normalized $\mathrm{Na}^{+}$currents are plotted versus pulse number for $30 \mathrm{nM}$ $\Pi \mathrm{TX}(\mathrm{O})$ and $1 \mu \mathrm{M} \Pi \mathrm{TX}(\bullet)$. Calibration, $2 \mathrm{msec}, 5 \mathrm{nA}$.

The effect of low concentrations of TTX on the $\mathrm{Na}^{+}$conductance was also examined by incubating myoballs with a low concentration of TTX in TEA-Ringer's, recording the inhibition of $\mathrm{Na}^{+}$currents, washing out the TTX, and recording the increase in $\mathrm{Na}^{+}$current. In this series of experiments, myoballs were incubated with TEARinger's containing $10 \mathrm{nM}$ TTX for more than 10 min until steadystate inhibition of $\mathrm{Na}^{\prime}$ conductance was obtained. Then $\mathrm{TT}$ was washed out by perfusing the dish with TEA-Ringer's containing no toxin. $\mathrm{Na}^{+}$currents were reversibly inhibited $22.2 \pm 2.7 \%(n=3)$ by $10 \mathrm{nM}$ TTX. Assuming $K_{D}$ values for high and low affinity sites of $10.0 \mathrm{nM}$ and $2.8 \mu \mathrm{M}$, respectively, and one-to-one binding of TTX to $\mathrm{Na}^{+}$channels, these results suggest that $44.9 \pm 5.3 \%$ of the $\mathrm{Na}^{+}$ current is mediated by $\mathrm{Na}^{+}$channels with high affinity $\mathrm{TTX}$ receptor sites, and $55.1 \%$ is mediated by those with low affinity sites on these three myoballs.

Frequency dependence of TTX block. Mammalian cardiac muscle cells have TTX-insensitive sodium channels (Dudel et al., 1967; Baer et al., 1976; Cohen et al., 1981) which have the same profile of neurotoxin sensitivity as those in cultured skeletal muscle cells (Catterall and Coppersmith, 1981). Frequency dependence of TTX block was reported for TTX-insensitive sodium channels of rabbit cardiac cells (Cohen et al., 1981) but has not been reported for TTXsensitive $\mathrm{Na}^{+}$channels. When rat myoballs were incubated in $1 \mu \mathrm{M}$ TTX, frequency-dependent inhibition of $\mathrm{Na}$ current was observed. In Figure $4 A$, the myoball was stimulated with depolarizing test pulses to $-15 \mathrm{mV}$ from a holding potential of $-120 \mathrm{mV}$ at $2 \mathrm{~Hz}$. The $\mathrm{Na}^{+}$ current was decreased by each test pulse in an exponential manner and reached a steady-state level of $61.2 \%$ of the amplitude of the first current (Fig. 4C). To obtain half-maximum inhibition of the frequency-dependent block, 1.22 pulses were required at this stimulus condition. The time constant of the recovery from the frequencydependent $T \mathrm{TX}$ block was determined by measuring the current amplitude at 20,30, and $60 \mathrm{sec}$ after ceasing the repetitive 15 depolarizing pulses (data not shown). The time constant of the recovery was $35.1 \pm 5.4 \mathrm{sec}(\mathrm{SD} ; n=2)$.

In contrast, little frequency-dependent block by TTX was observed in the presence of 5,10 , or $30 \mathrm{nM} \mathrm{TTX}$ in the frequency range of
0.2 to $8 \mathrm{~Hz}$ on four myoballs examined (Fig. $4 B$ and $C$ ). Therefore, as observed previously in other cell types, block of TTX-sensitive $\mathrm{Na}^{+}$channels by TTX is not frequency dependent, whereas block of TTX-insensitive $\mathrm{Na}^{+}$channels is frequency dependent.

\section{Discussion}

Sodium channels in rat muscle fibers developing in vitro. Our results show directly that individual embryonic rat muscle fibers developing in vitro in the absence of innervation have physiologically active forms of both TTX-sensitive and TTX-insensitive sodium channels in their surface membrane. Thus, innervation is not required for the initial appearance of high affinity $\Pi X$ receptor sites (Sherman and Catterall, 1982; Frelin et al., 1983; Sherman et al., 1983) or of functional TTX-sensitive sodium channels (this report). However, innervation in vivo is required to achieve a stable adult level of TTXsensitive sodium channels (Sherman and Catterall, 1982) and to prevent the reappearance of TTX-insensitive sodium channels in adult mammalian skeletal muscle (tlarris and Thesleff, 1971; Pappone, 1980). The loss of TTX-insensitive sodium channels during development of rat skeletal muscle in vivo can be mimicked in vitro by co-culture with spinal cord explants (Ziskind and Harris, 1979) or growth in medium containing spinal cord extract (Kuromi et al., 1979), suggesting that a chemical mediator is responsible for the effect of innervation on TTX-insensitive sodium channels. TTXsensitive sodium channels are down-regulated by the electrical activity of developing muscle cells (Sherman and Catterall, 1984), but the mechanism responsible for innervation-dependent up-regulation of the number of TTX-sensitive sodium channels (Sherman and Catterall, 1982) remains uncertain.

The mean $\mathrm{Na}^{+}$conductance of the myoballs studied was $90 \mathrm{pS} /$ $\mu \mathrm{m}^{2}$ of cell surface at $35 \mathrm{mM} \mathrm{Na}{ }^{+}$. Extrapolating to a physiological $\mathrm{Na}^{+}$concentration of $135 \mathrm{~mm}$ using an apparent $K_{M}$ of $204 \mathrm{~mm}$ (Yamamoto et al., 1984) indicates a peak $\mathrm{Na}^{+}$conductance of 246 $\mathrm{pS} / \mu \mathrm{m}^{2}$. Pappone (1980) found a mean conductance of $710 \mathrm{pS} /$ $\mu \mathrm{m}^{2}$ in normal rat skeletal muscle fibers at $22^{\circ} \mathrm{C}$. Thus, the total $\mathrm{Na}^{+}$ conductance of the myoball surtace membrane is approximately $35 \%$ of the adult level, indicating the presence of a substantial density of functional sodium channels. Of this $\mathrm{Na}^{+}$conductance, approximately $68 \mathrm{pS} / \mu \mathrm{m}^{2}$ is mediated by TTX-sensitive sodium channels, $10 \%$ of the adult value.

The membrane potentials at which half-maximal activation and inactivation of $\mathrm{Na}^{+}$current in rat myoballs were observed were -31 $\mathrm{mV}$ and $-74 \mathrm{mV}$, respectively. Pappone (1980) found values of -52 $\mathrm{mV}$ and $-89 \mathrm{mV}$ for rat extensor digitorum longus fibers cut in $\mathrm{CsF}$, whereas Adrian and Marshall (1977) obtained half-maximal activation and inactivation at $-47 \mathrm{mV}$ and $-80 \mathrm{mV}$, respectively, for intact fibers from the same muscle. Thus, both activation and inactivation of sodium channels in rat myoballs appear to occur at more positive membrane potentials than in innervated adult muscle fibers. However, we report values before the shift of voltage-dependent parameters observed after making a seal (see "Materials and Methods"). Values obtained $1 \mathrm{hr}$ after seal formation would be close to those reported for adult muscle.

Previous studies have demonstrated a close similarity of pharmacological properties of TTX-insensitive sodium channels in rat cardiac muscle and skeletal muscle cells (Catterall and Coppersmith, 1981). Our results extend this comparison to frequency dependence of TTX action (Cohen et al., 1981; Fig. 4). Thus, we propose that frequency-dependent block by TTX is a general characteristic of TTX-insensitive sodium channels that distinguishes them from the TTX sensitive sodium channcls in nerve and adult muscle. This property may be considered a third distinguishing characteristic of these two sodium channel subtypes along with their affinity for TTX and STX at neurotoxin receptor site 1 (Harris and Thesleff, 1971; Pappone, 1980) and their affinity and specificity for binding of scorpion toxins and sea anemone toxins at neurotoxin receptor site 
3 (Lawrence and Catterall, 1981a, b; Sherman et al., 1983; Frelin et al., 1984a, b).

Comparison with previous results. Two previous studies reached opposite conclusions concerning the functional activity of TTXsensitive sodium channels in rat muscle cells developing in vitro (Frelin et al., 1983; Sherman et al., 1983). Our present results with the patch voltage clamp method agree closely with earlier conclusions based on measurements of neurotoxin-activated ion flux (Sherman et al., 1983). $K_{D}$ values for the high affinity sites (2.1 nM versus $13 \mathrm{nM}$ ) and low affinity sites (1.8 $\mu \mathrm{M}$ versus $3.2 \mu \mathrm{M})$ are in close agreement. In addition, incubation of cultured rat muscle cells with veratridine plus scorpion toxin which preferentially activate TTXsensitive sodium channels (Lawrence and Catterall, 1981a; Sherman et al., 1983) results in $41 \%$ of the influx mediated by TTX-sensitive $\mathrm{Na}^{+}$channels and $59 \%$ by TTX-insensitive channels (Sherman et al., 1983). This value compares favorably with the $27 \pm 14 \%$ (SD) of $\mathrm{Na}^{+}$current mediated by TTX-sensitive sodium channels in the present voltage clamp experiments, since both classes of channels should be activated to an equivalent extent by membrane depolarization in these studies.

The methods used in previous studies of sodium channels in rat skeletal muscle by Frelin et al. (1983) provide a possible basis for interpretation of the apparent lack of $\mathrm{Na}^{+}$conductance mediated by TTX-sensitive sodium channels. In their ion flux studies, sodium channels were activated by veratridine plus sea anemone toxin. This treatment activates TTX-insensitive sodium channels preferentially (Lawrence and Catterall, 1981a; Sherman et al., 1983; Гrelin et al., 1984a). Under these conditions, we also observed no component of ${ }^{22} \mathrm{Na}^{+}$influx with high affinity for TTX (Sherman et al., 1983). Thus, it is likely that the conditions selected for activation of $\mathrm{Na}^{+}$channels by neurotoxins obscured a small component of ${ }^{22} \mathrm{Na}^{+}$influx with high affinity for TTX by preferentially activating the channels with low affinity for $\Pi \mathrm{TX}$.

Frelin et al. (1983) also observed no effect of $50 \mathrm{nM}$ TTX on the action potential of cultured rat muscle cells, suggesting that there were no functional sodium channels with high affinity for TTX. However, in the original description of TTX-insensitive sodium chan nels in denervated rat muscle by Harris and Thesleff (1971), measurements of action potentials in the presence of various concentrations of $T T X$ did not detect TTX-sensitive $\mathrm{Na}^{+}$channels despite the fact that $80 \%$ of the $\mathrm{Na}^{+}$current measured in voltage clamp is mediated by $\mathrm{Na}^{+}$channels with high affinity for $\mathrm{TTX}$ (Pappone, 1980). Evidently, the $20 \%$ of the sodium channels that have low affinity for $\Pi \mathrm{TX}$ are sufficient to mediate an action potential of nearly normal amplitude and rate of rise (Pappone, 1980). This nonlinear relationship between action potential parameters and $\mathrm{Na}^{+}$current makes it difficult to interpret results from action potential recordings alone. Since this method does not detect $80 \%$ TTX-sensitive $\mathrm{Na}^{+}$ channels in denervated rat muscle, it seems probable that it also would have failed to detect the $27 \%$ TTX-sensitive $\mathrm{Na}^{+}$channels that we have observed in whole cell patch clamp of rat myoballs, even if they were present in the cells studied by Frelin et al. (1983) Therefore, we believe these previous data are not inconsistent with the presence of functional TTX-sensitive sodium channels in rat muscle cells.

During our preparation of these results for publication, another study of the inhibition of $\mathrm{Na}^{+}$currents in rat myoballs by TTX appeared (Frelin et al., 1984b). An apparent $K_{D}$ value of $70 \mathrm{nM}$ for block of $\mathrm{Na}^{+}$currents in rat myoballs by $\Pi \mathrm{TX}$ was reported, and it was concluded that all of the $\mathrm{Na}^{+}$current was mediated by TTXinsensitive $\mathrm{Na}^{+}$channels. This is a surprising result and conclusion. TTX-sensitive $\mathrm{Na}^{+}$channels in mammalian skeletal muscle have $K_{0}$ values for TTX binding and action of approximately 5 to $20 \mathrm{nM}$ at 20 to $37^{\circ} \mathrm{C}$ (Ritchie and Rogart, 1977; Pappone, 1980; Sherman et al., 1983; this report). TTX-insensitive $\mathrm{Na}^{+}$channels in mammalian skeletal muscle have apparent $K_{0}$ values for inhibition of $\mathrm{Na}^{+}$currents by $\Pi \mathrm{TX}$ of 1 to $3 \mu \mathrm{M}$ whether measured by ion flux or voltage clamp (Kidokoro et al., 1975; Catterall, 1976; Sastre and Podleski, 1976;
Stallcup and Cohn, 1976; Pappone, 1980; Lawrence and Catterall, 1981a; Frelin et al., 1983, 1984a, b; Sherman et al., 1983; this report). Thus, the observed value of $70 \mathrm{~nm}$ falls between those expected for TTX-sensitive and -insensitive $\mathrm{Na}^{+}$channels and lies closer to the expected values for TTX-sensitive channels. Without further analysis, these results also do not seem inconsistent with the presence of a fraction of $\mathrm{Na}^{+}$current that is mediated by $\Pi \mathrm{TX}$ sensitive $\mathrm{Na}^{+}$channels with a $K_{D}$ of $13 \mathrm{~nm}$ as observed here.

Although our results show that rat muscle cells developing in vitro have a substantial complement of functional TTX-sensitive sodium channels, they do not provide evidence that all of the high affinity TTX receptor sites are associated with functional channels. Nonfunctional TTX-binding sites may exist in parallel with the functional TTX-sensitive $\mathrm{Na}^{+}$channels we have studied. Further experiments will be required to determine whether channel precursors with high affinity binding sites for TTX but no functional activity are observed during muscle development.

\section{References}

Adrian, R. H., and M. W. Marshall (1977) Sodium currents in mammalian muscle. J. Physiol. (Lond.) 268: 223-250.

Albuquerque, E. X., and J. E. Warnick (1972) The pharmacology of batrachotoxin. IV. Interaction with tetrodotoxin on innervated and chronically denervated rat skeletal muscle. J. Pharmacol. Exp. Ther. 180: 683-697.

Baer, M., P. M. Best, and H. Reuter (1976) Voltage-dependent action of tetrodotoxin in mammalian cardiac muscle. Nature 263: 344-345.

Catterall, W. A. (1976) Activation and inhibition of the action potential $\mathrm{Na}^{+}$ ionophore of cultured rat muscle cells by neurotoxins. Biochem. Biophys. Res. Commun. 68: 136-142.

Catterall, W. $\wedge .(1980)$ Neurotoxins that act on voltage-sensitive sodium channels in excitable membranes. Annu. Rev. Pharmacol. Toxicol. 20: 1543.

Catterall, W. A., and J. Coppersmith (1981) Phanmacological properlies of sodium channels in cultured rat heart cells. Mol. Pharmacol. 20: 533-542

Cohen, C. J., B. P. Bean, T. J. Colatsky, and R. W. Tsien (1981) Tetrodotoxin block of sodium channels in rabbit Purkinje fibers. J. Gen. Physiol. 78: 383-411.

Cullen, M. J., J. B. Harris, M. W. Marshath, and M. R. Ward (1975) An electrophysiological and morphological study of normal and denervated chicken latissimus dorsi muscles. J. Physiol. (Lond.) 245: 371-385.

Dudel, I., K. Peper, R. Rudel, and W. Trautwein (1967) The efferst of tetrodotoxin on the membrane current in cardiac muscle (Purkinje fibers). Pflugers Arch. 295: 213-226.

Frelin, C., P. Vigne, and M. Lazdunski (1983) $\mathrm{Na}^{+}$channels with high and low affinity tetrodotoxin binding sites in the mammalian skeletal muscle cell. J. Biol. Chem. 258: 7256-7259.

Frelin, C., P. Vigne, H. Schweitz, and M. Lazdunski (1984a) The interaction of sea anemone and scorpion neurotoxins with tetrodotoxin-resistant $\mathrm{Na}^{+}$ channels in rat myoblasts. Mol. Pharmacol. 26: 70-74.

Frelin, C., H. P. M. Vijverberg, G. Romey, P. Vigne, and M. Lazdunski (1984b) Different functional states of tetrodotoxin sensitive and tetrodotoxin resistant $\mathrm{Na}^{+}$channels occur during the in vitro development of rat skeletal muscie. Pflugers Arch. 402: 121-128.

Fukuda, J., G. D. Fischbach, and T. G. Smith (1976) A voltage clamp study of the sodium, calcium, and chloride spikes of chick skeletal muscle cells grown in tissue culture. Dev. Biol. 49: 412-424

Gonoi, T., B. Hille, and W. A. Catterall (1984) Voltage clamp analysis of sodium channels in normal and scorpion toxin-resistant neuroblastoma cells. J. Neurosci. 4: 2836-2842.

Hamill, O. P., A. Marty, E. Neher, B. Sakmann, and F. J. Sigworth (1981) Improved patch-clamp techniques for high resolution current recording from cells and cell-free membrane patches. Pflugers Arch. 391: 85-100.

Harris, J. B., and M. W. Marshall (1973) Tetrodotoxin-resistant action potentials in newborn rat muscle. Nature New Biol. 243: 191-192.

Harris, J. B., and S. Thesleff (1971) Studies on tetrodotoxin resistant action potentials in denervated skeletal muscle. Acta Physiol. Scand. 83: 382388.

Kidokoro, Y., S. Heinemann, D. Schubert, B. L. Brandt, and F. G. Klier (1975) Synapse formation and neurotrophic effects on muscle cell lines. Cold Spring Harbor Symp. Quant. Biol. 40: 373-399.

Kuromi, H., T. Gonoi, and S. Hasegawa (1979) Partial purification and characterization of neurotrophic substance affecting tetrodotoxin rensitivity of organ-cultured mouse muscle. Brain Res. 175: 109-118. 
Lawrence, J. C., and W. A. Catterall (1981a) Tetrodotoxin-insensitive sodium channels. Ion flux studies of neurotoxin action in a clonal rat muscle cell line. J. Biol. Chem. 256: 6213-6222.

Lawrence, J. C., and W. A. Catterall (1981b) Tetrodotoxin-insensitive sodium channels. Binding of polypeptide neurotoxins in primary cultures of rat muscle cells. J. Biol. Chem. 256: 6223-6229.

Nasledov, G. A., and S. Thesleff (1974) Denervation changes in frog skeletal muscle. Acta Physiol. Scand. 90: 370-380.

Nelson, P. G. (1975) Nerve and muscle cells in culture. Physiol. Rev. 55: 160.

Pappone, P. A. (1980) Voltage-clamp experiments in normal and denervated mammalian skeletal muscle fibres. J. Physiol. (Lond.) 306: 377-410.

Ritchie, J. M., and R. B. Rogart (1977) The binding of saxitoxin and tetrodotoxin to excitable tissue. Rev. Physiol. Biochem. Pharmacol. 79: 149.

Sastre, A., and T. R. Podleski (1976) Pharmacologic characterization of the $\mathrm{Na}^{+}$ionophores in L6 myotubes. Proc. Natl. Acad. Sci. U. S. A. 73: 13551359.
Sherman, S. J., and W. A. Catterall (1982) Biphasic regulation of development of the high-affinity saxitoxin receplor by innervation in rat skelelal muscle. J. Gen. Physiol. 80: 753-768.

Sherman, S. J., and W. A. Catterall (1984) Electrical activity and cytosolic calcium regulate levels of tetrodotoxin-sensitive sodium channels in cultured rat muscle cells. Proc. Natt. Acad. Sci. U. S. A. 81: 262-266.

Sherman, S. J., J. C. Lawrence, D. J. Messner, K. Jacoby, and W. A. Catterall (1983) Tetrodotoxin-sensitive sodium channels in rat muscle cells developing in vitro. J. Biol. Chem. 258: 2488-2495.

Stallcup, W. B., and M. Cohn (1976) Electrical properties of a clonal cell line as determined by measurement of ionic fluxes. Exp. Cell Res. 98: 277284.

Yamamoto, D., J. Z. Yeh, and T. Narahashi (1984) Voltage-dependent calcium block of normal and tetramethrin-modified single sodium channels. Biophys. J. 45: 337-344.

Ziskind, L., and A. J. Harris (1979) Reinnervation of adult muscle in organ culture restores tetrodotoxin sensitivity in the absence of electrical activity. Dev. Biol. 69: 388-399. 